\title{
Revisiting urban hierarchy and specialization from a maritime perspective
}

\author{
César DUCRUET ${ }^{1}$ \\ French National Center for Scientific Research (CNRS) \\ UMR 8504 Géographie-cités \\ 5, Cours des Humanités, F-93322 Aubervilliers, France \\ cdu@parisgeo.cnrs.fr
}

Pre-final version of the article published in Maritime Policy and Management, 47(3): 371-387

\begin{abstract}
Port-city relationships have attracted paramount attention from a variety of scientific disciplines for several decades, such as geography, history, planning, regional science, sociology, and economics to name but a few. Yet, the extent to which maritime traffic specialization obeys the same spatial distribution than other economic activities remains underexplored today. This article tackles this lacunae head on by proposing an empirical analysis of the way vessel tonnage per main categories of flows (e.g. containers, bulks, passengers) coincides with the demographic size of the world's coastal and inland city-regions, using novel data on global inter-port vessel movements and harmonized population data over the period 1977-2008. Our main results confirm that such traffic is far from being randomly distributed, as its volume, value, and diversity concentrate at the top of the urban hierarchy. This confirms both classic and recent works on scaling laws in urban systems, the latter being either more national in scope or more focused on immaterial rather than material flows. Lastly, we focus on European port cities in more detail including centrality indicators based on their position in the global maritime and sea-land network. This research motivates the need to further integrate physical connectivity into the study of cities and their development mechanisms.
\end{abstract}

Keywords: cities, complex systems, maritime transport, ports, scaling laws, specialization, urban systems, vessel traffic

\section{Funding}

This work was supported by the European Research Council under the European Union's Seventh Framework Programme (FP/2007-2013) / ERC Grant Agreement n. [313847] "World Seastems".

\section{Introduction}

Whether larger cities exhibit a wider economic (or functional) portfolio is an old question in geography (Pumain and Saint-Julien, 1978). Although this issue has been explored theoretically and empirically, mainly based on landward, national urban systems, it remains to date unanswered from a global city

\footnotetext{
${ }^{1}$ Author for correspondence. ORCID Number 0000-0002-0946-4712
} 
network perspective, especially in the realm of physical flows making globalization possible by the transport of goods. This article tackles this lacunae head on by bringing new evidence about the distribution of maritime traffic among the world's cities through different types of flows and in relation to cities' demographic weight. Main results convey to strong relationships between the way cities handle such flows and, at the same time, develop other types of activities - sometimes against the port function - in order to strive for competitiveness and keep their rank in the so-called "world city network" (Taylor and Derudder, 2016) where high-order services rather than freight flows are seen as a marker of their prominence. We demonstrate that materials flows remain essential to city prosperity and growth although this relationship changed across space and time in the last decades.

This article wishes to verify how the size and the functional diversity of cities have strong interrelationships. This relates to various schools of thought in geography and elsewhere, from regional science to physics. A lot has been written about cities as catalyzers of welfare and innovation (Pumain, 2006) and, at the same time, cities diversify their economy and economic base as much as their trade with other cities develops and grows, thereby increasing their dominance over other, often smaller, cities (Fujita et al., 1999). Yet, this legacy from past works mainly focused on immaterial, or service, activities, without giving much importance to cargo flows (Urry et al., 2015). So it is not still clear whether the volume and value of these freight / cargo flow are in line with the overall city's development today. From another point of view, geography and interdisciplinary research recently insisted on the need to look at the material (if not metabolistic) evolution of cities in relation to their needs as concentrated human settlements in the search for energy, construction materials, and manufactured goods flows as both production and consumer centers (Kennedy et al., 2015).

In this article, we go deeper in the understanding of the relationship between city size and specialization, based on the maritime side of their activity, "between flows and spaces" (Ng. et al., 2014). We are aware that a fully-fledged approach should also take into account land-based flows and thus incorporate inland, non-port cities, but our methodological choices partly solve this aspect. By using city-regions rather than city proper as the unit of analysis, we also take into account cities away from the coast but connected to maritime trade through more or less closely located port terminals. This is mainly true for cities located a few dozen kilometers from the coast (e.g. Caracas, Lima, Beijing) but also for cities located further away having a clear gateway access to the global shipping network, namely Johannesburg, Atlanta, and Berlin for instance.

This article has the potential to contribute to both urban, transport, and network studies as it mobilizes a vast array of theories and methodologies in order to verify the aforementioned hypotheses. The remainder is organized as follows. The second section proposes a non-exhaustive selection of stateof-the-art perspectives on cities, urban networks, and urban specialization, while recalling important advances in the understanding of maritime traffic distribution in the academic literature. This provides a base upon which section 3 carries on constructing a port city database based on inter-port vessel movement data and urban data over the period 1977-2008, notwithstanding important methodological specification such as cities' definition and sample size, etc. Main results are proposed in section 4 with a series of evidences that prove that although port-city relationships have weakened since the 1950s, we also observe the stability (and even reinforcement) of this crucial link. A closer look at particular cases is proposed in section 5 when analyzing how unevenly is the maritime traffic diversity index distributed across the world's cities. More applied implications are proposed in conclusion, based in the idea that port and non-port cities should consider strengthening their relationship with maritime trade, given the overwhelming importance of road transport within current logistics and value chains. 


\section{From land-based structures to maritime networks}

The French geographer Denise Pumain had been one of the first to find ways adapting USA and Swedish quantitative geography to the French urban system (Peris et al., 2018). Although other schools about urban systems emerged since then (i.e. the late 1970s), a consensus is yet to be seen among them when it comes to the definition and properties of urban networks (sometimes coined systems of cities). On the one hand, from the 1990s, New Economic Geography (Krugman, 1990) but also natural sciences (i.e. physics) investigated this field, sharing the idea that urban growth and evolution were dictated by specific laws. These are well-summarized in the work of Pumain et al. (2006), and more recently by Peris et al. (2018) for the relational perspective. The ideas developed by these diverse approaches are worth being confronted to our new empirical results as they encompass the whole social / natural science spectrum and is still up-to-date in terms of urban growth and evolution mechanisms. It was even demonstrated that "maritime and land transportation modes play a vital role in the growth of urban places" (Lugo, 2015, p. 322), as "port locations are significant nodes in the spatial network because they affect transport logistics to cities".

The main idea of Pumain et al. (2006) is to prove the existence of hierarchical properties commanding urban networks. Their main argument is that the "largest cities became larger because they were successful in adopting many successive innovations". Adaptation, imitation, and anticipation are key principles of this dynamic, although cities are not single actors but communities having divergent interests internally (Pumain, 1997). In theory and practice, larger cities should demonstrate a higher level of complexity or sophistication because "the most advanced technologies concentrate in largest cities", while "common place activities are ubiquitous, whereas old ones remain in small towns only". Wider urban functions have in common with port functions to have different technological standards and underwent different diffusion waves across the globe (Guerrero and Rodrigue, 2014).

Scaling laws are relations between physical quantities, the latter being defined in terms of powers, whereby a power of $x$ is expressed in the form $x^{\beta}$ where ${ }^{\beta}$ is a real number. We thus seek scaling relationships between city size and traffic size through the application of scaling laws, based on the idea that certain trades have different affinities with the urban economy. Power-laws are the main instrument to detect such mutual effects, as a particular statistical relationship between urban mass and traffic mass, namely $f(x)=a^{*} x^{-\beta}$ where $f(x)$ refers to population size, $a$ to a constant, $x$ to port traffic, and $B$ to the scaling exponent. Innovation remains a catalyst for competition as the main goal of ports is to increase their output measured, mainly, by the amount of tons or containers handled each year. Direct, indirect, and induced port-related employment data in cities (e.g. port services, industries, logistics, transport per mode, warehousing, maritime services such as insurance, brokerage, but also trading) is pitifully not so much available internationally, as it constitutes a much disaggregated category and is not counted the same from one port to the other.

Just like cities (Pumain et al., 2012), ports may be characterized and differentiated from each other in terms of local conditions (e.g. favorable harbor, trading culture, natural resources in the hinterland), geographic location (i.e. relative size and scope of its overseas activity, proximity to major sea lanes, upstream or downstream / deep-sea), but also by other processes common to other places or "complex systems" when looking at inter-port relationships or maritime networks for instance (see Ducruet, 2015 for a recent synthesis). According to classic works such as Vance (1970), port hierarchies may overlap urban hierarchies in colonial systems (mercantile model), as in the ideal-typical sequence model of Taaffe et al. (1963) or at the contrary, be at the periphery of urban networks like in the central place configuration centered inland (see Christaller, 1933), as criticized by James Bird (1977) when proposing the concept of gateway (see also Burghardt, 1970), and indirectly by Taylor et al. (2010) in their "central flow theory". 
Empirical tests of such a correlation mainly focused on container traffic versus urban population, demonstrating a decreasing trend at the global level (Ducruet and Lee, 2006) but at the same time, recognizing that the port-city physical and functional separation process so much debated in the literature was in fact differentiated regionally across the globe (Lee et al., 2008). Other empirical works focused more on regions rather than cities to understand their diversification over time, urban variables other than population being very scarce at the international level (Neffke et al., 2011), with applications to port regions demonstrating significant relationships between traffic specialization and regional economic specialization (Ducruet and Itoh, 2016).

Yet, no work has ever been done about the traffic specialization at the city level, which is the main goal of this article. The latter wishes to confront various theories to the case of ports and maritime transport with the hypothesis that despite the specifics of such a transport mode (i.e. long-distance connectivity, enormous importance for global trade, geophysical constraints of coastlines, technological requirements and evolutions, etc.), city regions possessing ports may exhibit similar features than more classic terrestrial landscapes analyzed by scholars, i.e. urban networks and hierarchies situated within land areas. We thus wish to test whether city size is an important determinant of maritime traffic diversity, since in most other urban hierarchies, "the number and diversity of functions increase with size [and] there is a systematic relationship between city size and the number of activities (housing, economic establishments, infrastructures), production (gross domestic product, revenues, wages, resources consumption), and the amount of incoming and outcoming flows (migrations, transport, and information)" (Pumain et al., 2012 - translated by the author). Previous works in the maritime realm, using either port tonnage statistical analysis in Europe (Ducruet et al., 2010) or complex network analyses in the world (Ducruet, 2017), demonstrated strong affinities between traffic diversity and traffic size at the port level. It is thus the aim of this research to go one step further, by getting urban and maritime dimensions closer to each other.

\section{Methodological specifications}

Measuring vessel traffic among ports of the world over more than 30 years was made possible using the largely untapped database provided by Lloyd's List Intelligence, the world's leader for maritime insurance. Its data contains very accurate information about more than $80 \%$ of the world fleet, including daily inter-port movements of vessels by type and subtype, flag, tonnage, operating company, year of built, vessel name and ex-names, etc. In total, we extracted four complete months a year of data (i.e. March, June, September, and December), due to the cost of this database, resulting in a total of 3,338,476 vessel movements. One vessel movement means a voyage sequence from one port of call to another along the whole trip of the vessel between two given dates. Traffic at ports was calculated as the sum of vessels' carrying capacities in deadweight tonnage (DWT). Each time a vessel calls at a given port during those four months we add up its total carrying capacity to the port resulting in total yearly traffic.

Traffic categories were redefined based on the 159 original subtypes, resulting in 6 main types each of which having a relatively balanced importance: containers (5,705 vessels), passengers and vehicles $(5,092)$, services of various kinds from pilot ships to salvage $(9,427)$, solid bulks $(10,377)$, liquid bulks $(12,984)$, and general cargo, the most populous category $(29,767)$. While an analysis based on 25 types may have been envisaged, certain fleets could not be equally disaggregated into subtypes (see Appendix 1). It was therefore preferred to analyze cities through main traffic types although certain subtypes may be more meaningful in terms of urban development, such as cement and asphalt as construction materials for buildings and roads for instance. Yet, traffic types are not particularly 
presumed to be more urban-sensitive according to their nature. Traffic is counted based on the total carrying capacity of vessels (i.e. assuming that vessels travel fully loaded) and there is no information whatsoever about the true quantity and origin/destination of cargo handled at the docks. No other data source may provide, however, an equivalent picture of world port traffic per main commodity type over 31 years. For these reasons, we weighted vessel capacities to better reflect the value of flows, their probability to stay around the port and to create employment, based on the method proposed by Charlier (1994) $)^{2}$. While this method is one of many other weighting rules, it provides a better assessment of traffic's local economic linkages. It gives more importance to general cargo, which creates the most employment at port terminals, contrary to bulks, and reduces the weight of traffic with lesser spatial friction (Guerrero, 2014) such as bulks, containers, and roll-on / roll-off. Appendix 2 shows a peculiar evolution of general cargo since this category had been increasingly containerized overtime, like other products of which bulks and automobiles. Its world share evolved from $62.2 \%$ in 1977 to $29.7 \%$ in 2008 , i.e. a decrease of more than half of its importance. One reason is, for instance, the growing containerization of several commodities including fresh products (Rodrigue and Notteboom, 2015).

The chosen definition of cities in this research is based on the extent of their morphological area, which may include one or more ports and port terminals. This corresponds to the definition of cities by Moriconi-Ebrard (1994) who for the first time provided harmonized population data over the period 1950-1990. This time series was complemented by other data sources offering a similar definition for more recent years (see Ducruet et al., 2018 for a more detailed explanation). The most important to retain is that such city-regions are defined in a wider way than their sole administrative function or boundaries, the latter excluding nearby terminals located outside the city proper's jurisdiction. Thus city-regions may include one or more ports and urban cores depending on the spatial extent of urbanization, the pattern of road networks, and elevation. Another methodological step was to assign vessel flows not only to city-regions but also to larger, nearby cities should they locate inland or along the coastline, namely extended urban areas. Such spatial units constitute regional economic cores that are likely to explain the activity of most port terminals situated in their vicinity. For instance, the ports of Wilmington, El Segundo, San Pedro, Los Angeles, and Marina del Rey belong to the same city-region "Los Angeles", while the extended urban area "Los Angeles" includes the city-regions of Los Angeles, Long Beach, Ventura, and Huntington Beach, each of them containing one or more ports. Overall, the database assigned 5,712 ports to 2,283 port city-regions and 1,732 extended urban areas, while certain ports remaining non-urban due to the absence of population data due to their status of small coastal villages away from any extended urban area. Yet we do not include cities standing further inland such as Atlanta (Savannah), Johannesburg (Durban), and Berlin (Rostock) due to physical distance and the fact that often, such cities may use multiple gateways to access maritime trade, thereby needing a more advanced methodology based on a global road network information (see Berli et al., 2018 for the Australian case).

To verify the outcome of our methodological choices, Figure 1 compares the different affinity of weighted and non-weighted vessel traffic to port cities (city-regions) and extended urban areas. As a matter of fact, extended urban areas are much more correlated with traffic size along the study period, just like weighted traffic is much more correlated with city size on average. Weighted traffic stands 1 point higher in significance compared with raw traffic, while extended city-regions stand 3 points higher than port cities on average. We thus only retain those two facets as they offer the best potential to study port-city relationships. A correlation of about $50 \%$ along the study period is promising given

\footnotetext{
${ }^{2}$ Charlier (1994)'s weighting method consists in dividing the tonnage of the following traffics by the numbers in parentheses: crude oil (12), other liquid bulks (9), solid bulks (6), containers and ro-ro (3), and general cargo (1).
} 
the aforementioned inconveniences of vessel movement data, the complexity of global supply chains, and the fact that cities are often only one part of the true hinterland (or market area) of the ports.

[Figure 1]

\section{Traffic distribution and the urban hierarchy}

We start by observing the relative distribution of global vessel traffic per urban quantile (Figure 2) between 1977 and 2008 - see Appendix 3 for a description of quantile thresholds at four selected years. Results are striking: on average, two thirds (64.6 percent) of global vessel traffic concentrates in the largest cities (quantile 5). One likely explanation is that the largest cities continue to host the largest ports, despite abundant cases of port-city separation documented by scholars. Another explanation is that new ports were relocated outside but near the urban core, such as New Jersey for New York and Maasvlakte for Rotterdam, so that their traffic is counted as "urban" in the analysis but also in the way statistics are delivered since old port and new port keep being managed by the same authority. This is less evident in cases such as London where traffic had been rerouted towards peripheral location situated more than 200 kilometers away (e.g. Felixstowe) and managed by a different, often private, company (i.e. Hutchinson Whampoa). Traffic distribution among quantiles follows the urban hierarchy in a stable manner, from the smallest to the largest cities.

[Figure 2]

The slight decline of correlation from 0.6 to 0.5 since the late 1980 s observed in Figure 1 is masked here by the sum of traffic that reduces the influence of outliers. Outliers may be, as in the case of London and Felixstowe, large cities with small ports and large ports in small cities, resulting from portcity separation processes affecting large maritime cities but also transshipment development to better connect global sea lanes as well as hinterlands, without necessarily passing through a large city. Such outliers confirm early models of port-city evolution whereby large port cities witnessed a stagnation or even decline of their port and maritime activity (see a recent synthesis by Monios et al., 2018), the latter being shifted to smaller places with cheaper and more available land, often located along major trunk lines such as intermediary hubs (Rodrigue and Notteboom, 2010). But because urban activities are still important to the ports and maritime sector (Hall and Jacobs, 2012), this rerouting and optimization in fact rarely occurs at the smallest cities. Conversely, large transshipment hubs located in small cities rarely foster urban economic growth despite their high connectivity and important traffic volume (Slack and Gouvernal, 2016). Such trends correspond to the increasing size of containerships in the mid-1990s, resulting from the liberalization of the liner shipping sector and vessel size fostering route optimization as well as traffic concentration at intermediate hubs along trunk lines but on relatively small economies such as islandic or peninsular ports (e.g. Caribbean, the Mediterranean, Southeast Asia). At the contrary, the maintained importance of the largest cities at the top of traffic hierarchy rests on fast-growing Asian port cities where port and city remain tightly interdependent in the absence of hinterland competition (Lee et al., 2008) as in Hong Kong and Singapore but also China and the rest of East Asia concentrating enormous traffic amounts of all kinds. More recently, certain global cities such as London, Taipei, Jakarta, Osaka, and Tokyo reinvested in new container terminals closer to their respective urban cores, to serve cost and time instead of passing through faraway "outports" by trucking, and for environmental reasons as well to reduce carbon emissions along congested landside transport corridors (El Hosni, 2017).

When it comes to traffic types, Figure 3 (left) confirms that higher-valued traffic more significantly correlates with city size (general cargo, containers). This evidence also confirms the work of Charlier 
(1994) as general cargo exhibits the highest correlation, even more than total traffic, as such a traffic may be less valuable than containers but creates more employment in port cities as it is not containerized and requires more labor at the docks. Except for weighted traffic, bulks are much less significantly correlated with urban population, being more place-dependent (e.g. natural resources for exports from mining sites or oil fields), and passenger traffic being quite specific in terms of circulation patterns due to climate conditions and seasonality (Rodrigue and Notteboom, 2013). Lastly, port services have the lowest correlation with city size and this correlation had even decreased since the middle of the study period. Those services are common to nearly every port in the world and are not specifically related with urban activities. As seen in Appendix 1, this category also contains very specific vessels related with rescue, research, and other activities not even related with shipping itself.

[Figure 3]

Another approach is to test our initial hypotheses is based on scaling laws applied to urban population and traffic volume per traffic type (see Appendix 4 for an example of $\beta$ value calculation). Our results (Figure 3, right) are only partly in line with the classification proposed by Bettencourt et al. (2009) based on the $\beta$ value that is the slope exponent of the power-law line inserted in a log-log plot. We observe that all $\beta$ values fall under 1 , thus making maritime traffic a very basic urban function compared with more advanced ones such as wages, GDP, patents, inventors, R\&D employment, housing costs, and advanced producer services (APS). This confirms the work of Jacobs et al. (2011) demonstrating that the concentration of maritime APS in cities is better explained by the presence of other APS and urban rather than port indicators.

Thus, scaling laws exhibit a sublinear relationship between urban population and maritime traffic. This means that maritime (and port) activities' driving force for cities is characterized by optimization and efficiency but at the same time, long-term stagnation in terms of stimulating urban growth. It is in line with recent works on the decreasing role of maritime transport in urban growth (Bretagnolle, 2015), the first being an old, outdated innovation cycle and the second stimulated by more recent innovation cycles such as R\&D and APS (Pumain et al., 2009). Although ports and port terminals are more and more capital-intensive, such facilities remain in the category of (urban) infrastructures allowing economies of scale thanks to their size, but remained physically constrained just like biological organisms. In this respect, ports fall into the category of other essential (but basic) infrastructure such as gasoline stations, gasoline sales, length of electrical cables, road surface, etc. despite the fact that in our study, the port is not studied in terms of infrastructure but in terms of traffic, the latter being only partly dependent on infrastructure size (e.g. number of cranes, quay length and depth) as quality also plays a role (i.e. terminal productivity and efficiency) (Notteboom, 2004).

Nevertheless, scaling exponents per traffic type are not randomly distributed, and their evolution overtime is very interesting in many ways. General cargo and liquid bulks are closer to 1 , meaning that, according to Bettencourt et al. (2009), those flows correspond to a linear (or exponential) relationship which driving force is "individual maintenance" in terms of urban growth, and often correspond to activities such as total establishments, total employment, household power and water consumptions. $\beta$ values remaining under 0.5 all along the study period have, therefore, very limited relationship with (or impact on) urban activity, for the reasons cited above. However, general cargo underwent a gradual decreased of its $\beta$ value, contrary to containers, the most advanced shipping technology, which $\beta$ value increased mainly from the mid-1990s. This means that there is a resemblance between urban activities and port activities when comparing our results with the work of Pumain et al. (2009) on scaling laws where the most dynamic economic activities (cf. innovation, production, wages, high costs) exhibit a superlinear relationship with city size. Perhaps, the continued growth of containers' $\beta$ value after 2008 would also become superlinear, container shipping being highly selective and much concentrated in a 
small number of large and diversified port cities. This was demonstrated using other methods at the regional (subnational) level by Ducruet and Itoh (2016): the most valuable traffics concentrate in regions specialized in the tertiary sector, with a GDP per capita higher than national average, and high population densities.

Our results, despite differences with the literature on other urban functions, share important similarities that should be further underlined. First, the largest cities concentrate the bulk of global maritime traffic, while the correlation between traffic and population has remained stable and significant between 1977 and 2008. Second, the most valued and employment-generating traffic is best correlated with city size, while containers, the latest technological innovation in maritime transport which truly started to spread globally in the 1970s, is identified as a vector of urban dynamism in terms of scaling laws. As confirmed by the recent work of Pumain and Rozenblat (2019), "Superlinear scaling thus reveals the metropolisation trends that are produced in the urban system, according to [the] evolutionary theory perspective, by the hierarchical diffusion of innovation waves". Containerization, without which globalization and world trade would have been much limited in speed and scope (Frémont, 2015; Bernhofen et al., 2016), closely corresponds to such a wave (see alqo Guerrero and Rodrigue, 2014) and has a particular role in urban development despite the large amount of literature focusing on the dereliction of port-city linkages. This motivates us to go further into the understanding of the maritime traffic specialization of cities in the next section.

\section{Traffic specialization vs. diversity}

One first approach to the understanding of traffic specialization or diversity is to look at the number of different traffic types handled by cities (Figure 4, left). Results are striking, as the quantile of the largest cities dominates by far other quantiles. While this distribution is stable overtime, the largest cities keep expanding their traffic portfolio contrary to smaller cities, for which the average number of traffic types remains stable from the middle of the period. This simple result demonstrates that the largest cities are also the most diversified on average. To go one step further, we use the diversity index proposed by Duranton and Puga (2000) that is in fact the inverse of the specialization index proposed by Isard (1960) previously. The latter corresponds to the sum of the absolute differences in shares for all ports compared with the world average based on our six traffic types. In other words, this index summarizes the extent to which a city is diversified (higher than 1) or specialized (lower than 1). The distribution of the obtained traffic diversity index across the five urban population quantiles also exhibits very clear affinities (Figure 4, right) as again, the largest cities appear to be the most diversified, far more than smaller ones. All quantiles underwent a downward trend contrary to the average number of traffic types, but the gap between largest cities and smaller cities had widened. While all cities handle a greater variety of traffic overtime, at the same time they become closer to the world average. Yet, the largest cities maintained and even increased their traffic diversity, contrary to other cities which stabilized or even specialized.

[Figure 4]

The correlation between traffic diversity and city size (Figure 5, left) is moderately significant but exhibits an increase overtime, from 0.24 in 1990 to 0.38 in 2008, notwithstanding certain fluctuations. A nearly opposite trend is observed for the correlation between diversity and total vessel traffic, which decreased from 0.53 in 1990 to 0.39 in 2008. Respective evolutions converge during the 2000s to such an extent that they practically overlap. Traffic diversity is thus explained by city size as much as by traffic size in recent years, both of them at the level of extended urban areas. However, a look at the situation in 2008 (Figure 5, right) helps us to identify outliers and the possible forces behind their 
emergence. To support this analysis, we applied a statistical test using the loglinear function to estimate $y$-axis values and compare them with actual values. Although the correlation between estimated and observed values exhibits homoscedasticity, we concentrate our discussion on the top 30 negative and positive values of the difference between estimated and observed.

[Figure 5]

Cities whose diversity index is much lower than what their city size would predict can be depicted by four main elements. First, Great Lakes cities have in common to have experienced industrial decline resulting in traffic loss, also partly due to their eccentric situation vis-à-vis major sea lanes compensated by land transport (i.e. Chicago, Toronto, Cleveland, Milwaukee, Detroit, and Toledo). Without a proper industrial base, such cities keep handling basic commodities in a relatively few types such as solid bulk (e.g. construction materials, urban waste). The same applies to upstream river cities like Paris and Brussels in Europe (but also Pyongyang and Yangon in Asia) that carry mainly low-valued goods by water, the rest being shipped by trucks to/from distant areas. Thus and second, dependence upon multiple outer terminals is a key factor in the case of Paris, France's core economic region which main port is actually Antwerp in Belgium, so that the majority of Paris warehouses located in the northeastern suburbs of the city. The rest of Paris' maritime traffic is handled also relatively far at the French ports of Le Havre and Marseilles, so that the city is not self-sufficient in terms of port activities. In addition, coal river shipping ceased to be a traffic generator for France and Paris as most electricity became nuclear in the 1970s, and oil river shipping had been gradually replaced by long-distance pipelines. Rostov (Russia), Joao Pessoa and Porto Alegre (Brazil) are other examples of important cities served by water but being physically constrained - the same applies to Warri and Port Harcourt in Nigeria but also inland non-port cities like Orlando (USA), Tegucigalpa (Honduras), and Adana (Turkey) served by nearby ports. Third, traffic specialization may occur in large cities due to many other locational effects of which historical legacy for naval cities (Toulon, France), tourism (Acapulco, Mexico), and natural resource export (Sumenep, Indonesia). Fourth, such cities are also important conurbations so that their urban morphology inflates their population number compared with their actual vessel traffic size and diversity, as seen in the cases of San Diego/Tijuana, Tianjin/Beijing, Washington/Baltimore, Port Klang/Kuala Lumpur, and Rabat/Salé. Narrowing population count to the sole port city would exclude such outliers but at the same time, this would produce other outliers for which the conurbation makes full sense physically and functionally.

The underlying mechanisms are harder to detect for cities whose diversity index is much higher than what their city size would predict. Yet the reference to the work of Ducruet et al. (2010) at the port level is a useful help as such outliers had in common, in a European context, to locate away from the continental economic core (or hinterland) where competition is fierce. Distance was seen by Ducruet et al. (2010) as a complement to other geographic features such as physical barriers like islandic location, peninsular location, etc. Their abnormal traffic diversity was explained by the fact that such ports acted as main gateways to their country or region in the absence of competition not only with other ports but also with other modes (i.e. difficult accessibility by land). Still, Europe's largest port, Rotterdam, stood out by its highest diversity index, being at the top of competition. Europe being a specific maritime region (see also Lee et al., 2008), it is interesting to confront our results to this previous study. First, the periphery factor is apparent in the case of Las Palmas (Spain), Perth (Australia), Sendai (Japan), and Vancouver (Canada) as such cities are regional capitals away from the national economic core and provide their surrounding region with most essential traffics. Second, the national gateway factor goes along with the first, with certain cities being national capitals and largest national ports (San Salvador, Mombasa, Tokyo, Manama, Haifa/Tel-Aviv), just largest national ports (Durban, Rotterdam, Ho Chi Minh City, Koper, Aqaba), and regional capitals (Murcia, Antofagasta, 
Izmir, Hodeidah, Wellington). Many of those cities have developed proactive policies to palliate their peripherality and relative small local economic base by the catchment of important liner shipping services. Vancouver's Asia-Pacific gateway corridor initiative is one well-known case, willing to exploit the city's proximity to U.S. markets, U.S. West coast ports deficiencies and Panama Canal restrictions. Rotterdam is a textbook example of a relatively small city having become the world's largest port during several decades, being rather unique given the scale of its recent developments.

The world distribution of traffic diversity in relation to urban population at four selected years (Figure 6) complements the above findings by the fact that the overall spatial pattern is rather stable as the largest cities belong to the highest traffic diversity class. The exception of Chicago and other Great Lakes port cities well appears and it adds to our previous finding the temporal dimension, as such cities gradually became specialized from an initially diversified profile. The lower diversity of smaller cities is well apparent in certain areas where such profile concentrates, usually based on natural resource exploitation and export: Alaska and Western Canada (wood), northern Australia (coal), Scandinavia (oil, ores), and Southeast Asia (lumber). The largest cities have not shifted across diversity categories (based on natural thresholds) except from Sao Paulo/Santos (Brazil) and New York that, in accordance with previous Figure 4, lost in traffic diversity like the world average. The four years being mapped based on the same thresholds, it is interesting to observe the peculiar character of European cities in 1978 , most of them belonging to the class of the most diversified traffics. While the rest of the world also tends to appear more diversified than in other years, Europe remains unique by the number and concentration of small cities handling highly diversified traffic.

[Figure 6]

\section{Discussion and conclusion}

This article tackled the applicability of wider urban theories to the case of cities' maritime activity. While the maritime mode is not at all common in urban studies using a complex systems approach, it still carries nowadays about $90 \%$ of world trade volume. Thus, a great number of cities exert various maritime-related activities throughout the world, from cargo-handling activities of diverse traffic types to Advanced Produced Services (APS) in that sector. The main focus of this research is about vessel traffic patterns and distribution across the global urban hierarchy. We demonstrate that traffic size and diversity obey similar "laws" commanding the ordering of economic activities in cities (e.g. complex systems, power-laws), as observed in other domains. Although our results conclude that the maritime mode as a whole cannot account for a very innovative urban activity, main traffic types are not randomly distributed across the urban hierarchy. More valued and employment-generative traffics are more correlated with city size (i.e. general cargo and containers), followed by energy flows (liquid bulks) and basic commodities (solid bulks) while other traffics like passengers, vehicles and services are less. Our global analysis is thus in accordance with previous studies of national and continental urban systems based on other urban variables using employment or establishment data. Larger cities are more diversified than smaller cities in terms of traffic portfolio as seen by their higher score and number of traffic types. This occurs although the global scale does not correspond to a bounded territorial area, a nearly borderless space where theoretically any port may connect any other port (Bird, 1984).

Such results thus confirm that huge technological and operational transformation of the ports and maritime sector, together with its spatial consequences, did not so much erode the functional portcity relationship on the level of city-regions and extended urban areas in recent decades. We conclude that the immediate hinterlands of ports remain, on average, essential to port activity as cities keep 
being the main origins and destinations of maritime flows, even when excluding more distant, inland cities, and the full door-to-door perspective of logistics and value chains. In view of the recent works on the "global competitiveness of port cities" (OECD, 2014) and on the "return of the port within the city" (El Hosni, 2017), one may derive a number of policy implications from such an analysis. Beyond the fact that cities are important to ports and vice-versa, our results motivate focusing on positive externalities such as the reduction of trucking distance between city and port. Port-city evolutionary models proposed in the 1960s such as Anyport (Bird, 1963) and its followers saw physical and functional separation as ineluctable, following the Second Industrial Revolution and before the domination of automobiles and trucks that deeply transformed land transport. Road transport thus became inevitable to serve most of the world's cities and hinterlands to/from port terminals. But it is, today, seen by many organizations as one of the worst negative externalities, against which water transportation is one possible solution. However, the failure of certain projects such as the EU Marco Polo shortsea shipping ones targeting land-sea modal shifts is revelatory of the difficulty to revert the legacy of past policies. The argument by which such a shift would provoke dramatic employment losses for the road transport sector due to economies of scale in maritime transport does not hold when thinking of the revival of many bypassed, sometimes derelict, port areas that would receive these flows and perhaps, direct and indirect employment effects. One only disagreement of a port city-based transport policy, especially in a deregulated, competitive environment, is the risk of overconcentration. But as port system evolutionary models also showed quite clearly is the fact that port concentration often goes along with inland corridor concentration in both emerging (Taaffe et al., 1963) and old industrial economies.

Further research shall lean towards three main directions. First, an extension of the time period would be necessary to verify whether the observed trends still hold in the past and in the more recent decade, making it possible to verify whether the pre-trucking world functioned so much differently than the current world. Such a longer-term perspective would require to extract data in same ways from the same source or to consider other possibilities but alternatives appear to be scarce. Second, the extension of our sample to whole continental urban systems would be fruitful, to check the maritime character (albeit indirect) of inland, non-port cities and the intermediate role of port cities - should they be city-regions or extended urban areas - between them. This would require the development of a robust Geographical Information System (GIS) capable of computing land-sea accessibility measures as seen in the work of Berli et al. (2018). Last and not least, additional urban data may be gathered whenever possible to conduct multivariate analyses combining traffic and local socio-economic indicators on parent or other (shipping, logistics) activities. To achieve such a goal, a zoom on a single country or continent (Ducruet and Van der Horst, 2009) might be envisaged to reduce the difficulty of finding and/or harmonizing urban data at the global scale.

\section{References}

Berli, J., M. Bunel, and C. Ducruet. 2018. "Sea-land interdependence in the global maritime network: the case of Australian port cities." Networks and Spatial Economics 18 (3): 467-471.

Bernhofen, D. M., Z. El-Sahli, and R. Kneller. 2016. "Estimating the effects of the container revolution on world trade." Journal of International Economics 98: 36-50.

Bettencourt, L. M. A., J. Lobo, and G. B. West. 2009. "The self-similarity of human social organization and dynamics in cities." In Complexity Perspectives on Innovation and Social Change, edited by D. Lane, D. Pumain, S. van der Leeuw, and G. B. West, 221-236. Dordrecht: Springer. 
Bird, J. 1963. The Major Seaports of the United Kingdom. London: Hutchinson.

Bird, J. 1977. Centrality and Cities. London: Routledge \& Kegan Paul.

Bird, J. 1984. "Seaport development: Some questions of scale." In Seaport Systems and Spatial Change, edited by B. S. Hoyle and D. Hilling, 21-41. Chichester: Wiley.

Burghardt, A. F. 1970. "A hypothesis about gateway cities." Annals of the Association of American Geographers 61 (2): 269-285.

Bretagnolle, A. 2015. "City systems and maritime transport in the long term." In Maritime Networks: Spatial Structures and Time Dynamics, edited by C. Ducruet, 27-36. London and New York: Routledge.

Charlier, J. 1994. "Sur le concept de tonnages pondérés en économie portuaire." Les Cahiers Scientifiques du Transport 29: 75-84.

Christaller, W. 1933. Die Zentralen Orte in Süddeutschland. Jena: Gustav Fischer

Ducruet, C. 2015. "Maritime flows and networks in a multidisciplinary perspective." In Maritime Networks: Spatial Structures and Time Dynamics, edited by C. Ducruet, 3-26. London and New York: Routledge.

Ducruet, C. 2017. "Multilayer dynamics of complex spatial networks: The case of global maritime flows (1977-2008)." Journal of Transport Geography 60: 47-58.

Ducruet, C., S. Cuyala, and A. El Hosni. 2018. "Maritime networks as systems of cities: The long-term interdependencies between global shipping flows and urban development (1890-2010)." Journal of Transport Geography 66: 340-355.

Ducruet, C., and H. Itoh. 2016. "Regions and material flows: Investigating the regional branching and industry relatedness of port traffic in a global perspective." Journal of Economic Geography 16 (4): 805-830.

Ducruet, C., H. R. A. Koster, and D. J. Van der Beek. 2010. "Commodity variety and seaport performance." Regional Studies 44 (9): 1221-1240.

Ducruet, C., and S. W. Lee. 2006. "Frontline soldiers of globalisation: Port-city evolution and regional competition." Geojournal 67 (2): 107-122.

Ducruet, C., and M. R. Van der Horst. 2009. "Transport integration at European ports: Measuring the role and position of intermediaries." European Journal of Transport and Infrastructure Research 9 (2): 121-142.

Duranton, G., and D. Puga 2000. "Diversity and specialisation in cities: why, where and when does it matter?" Urban Studies 37 (3): 533-555.

El Hosni, A. 2017. Le Retour du Port dans la Ville. Sarrebruck: Editions Universitaires Européennes.

Frémont, A. 2015. "A geo-history of maritime networks since 1945. The case of the Compagnie Générale Transatlantique's transformation into CMA-CGM." In Maritime Networks: Spatial Structures and Time Dynamics, edited by C. Ducruet, 37-49. London and New York: Routledge.

Fujita, M., P. Krugman, and A. J. Venables 1999. The Spatial Economy: Cities, Regions and International Trade. Cambridge \& London: MIT Press.

Guerrero, D. 2014. "Deep-sea hinterlands: Some empirical evidence of the spatial impact of containerization." Journal of Transport Geography 35: 84-94. 
Guerrero D., and J. P. Rodrigue. 2014. "The waves of containerization: Shifts in global maritime transportation." Journal of Transport Geography 35: 151-164.

Hall P. V., and W. Jacobs. 2012. "Why are maritime ports (still) urban, and why should policy makers care?" Maritime Policy \& Management 39 (2): 189-206.

Isard, W. 1960. Methods of Regional Analysis: An Introduction to Regional Science. Cambridge: MIT Press.

Jacobs, W., H. R. A. Koster, and P. V. Hall. 2011. "The location and global network structure of maritime advanced producer services." Urban Studies 48 (13): 2749-2769.

Kennedy C. A., I. Stewart, A. Facchini, I. Cersosimo, R. Mele, B. Chen, M. Uda, A. Kansal, A. Chiu, A. Kim, C. Dubeux, E. Lebre La Rovere, B. Cunha, S. Pincetl, J. Keirsteadi, S. Barles, S. Pusakak, J. Gunawan, M. Adegbile, M. Nazariha, S. Hoque, P. J. Marcotullio, F. Gonzalez Otharan, T. Genena, N. Ibrahim, R. Farooqui, G. Cervantes, and A. D. Sahin. 2015. "Energy and material flows of megacities." Proceedings of the National Academy of Sciences 112 (19): 5985-5990.

Krugman, P. 1990. Increasing Returns and Economic Geography. National Bureau of Economic Research. http://www.nber.org/papers/w3275

Lee, S. W., D. W. Song, and C. Ducruet. 2008. "A tale of Asia's world ports: The spatial evolution in global hub port cities." Geoforum 39 (1): 372-385.

Lugo, I. 2015. "Interplay between maritime and land modes in a system of cities." In Maritime Networks: Spatial Structures and Time Dynamics, edited by C. Ducruet, 322-329. London \& New York: Routledge.

Monios J., R. Berqvist, and J. Woxenius. 2018. "Port-centric cities: The role of freight distribution in defining the port-city relationship." Journal of Transport Geography 66: 53-64.

Moriconi-Ebrard, F. 1994. Geopolis: pour Comparer les Villes du Monde. Paris: Economica.

Neffke, F., M. Henning, and R. Boschma. 2011. "How do regions diversify over time? Industry relatedness and the development of new growth paths in regions." Economic Geography 87 (3): 237265.

Ng, A. K. Y., C. Ducruet, W. Jacobs, J. Monios, T. E. Notteboom, J. P. Rodrigue, B. Slack, K. C. Tam, and G. Wilmsmeier. 2014. "Port geography at the crossroads with human geography: between flows and spaces." Journal of Transport Geography 41: 84-96.

Notteboom, T. E. 2004. "Container shipping and ports: An overview." Review of Network Economics 3 (2): 86-106.

OECD (Organisation for Economic Cooperation and Development) 2014. The Competitiveness of Global Port-Cities. Paris: OECD.

Peris, A., E. Meijers, and M. van Ham. 2018. "The evolution of the systems of cities literature since 1995: Schools of thought and their interaction." Networks and Spatial Economics 18 (3): 533-554.

Pumain, D. 1997. “Pour une théorie évolutive des villes." L'Espace Géographique 26 (2): 119-134.

Pumain, D. 2006. Hierarchy in Natural and Social Sciences. Dordrecht: Springer.

Pumain, D., F. Paulus, C. Vacchiani-Marcuzzo. 2009. "Innovation cycles and urban dynamics." In Complexity Perspectives on Innovation and Social Change, edited by D. Lane, D. Pumain, S. van der Leeuw, and G. West, 237-260. Dordrecht: Springer. 
Pumain, D., F. Paulus, C. Vacchiani-Marcuzzo C., and J. M. Favaro. 2012. Lois d'Echelle et Diffusion des Innovations dans le Système Urbain. Paris: MASHS.

Pumain, D., and C. Rozenblat. 2019. "Two metropolisation gradients in the European system of cities revealed by scaling laws." Environment and Planning B 46 (9): 1645-1662.

Pumain, D., and T. Saint-Julien 1978. Les Dimensions du Changement Urbain. Paris: CNRS.

Rodrigue, J. P., and T. E. Notteboom. 2010. "Foreland-based regionalization: Integrating intermediate hubs with port hinterlands." Research in Transportation Economics 27 (1): 19-29.

Rodrigue, J. P., and T. E. Notteboom. 2013. "The geography of cruises: Itineraries, not destinations." Applied Geography 38: 31-42.

Rodrigue, J. P., and T. E. Notteboom. 2015. "Looking inside the box: evidence from the containerization of commodities and the cold chain." Maritime Policy \& Management 42 (3): 207-227.

Slack, B., and E. Gouvernal. 2016. "Container transshipment and logistics in the context of urban economic development." Growth and Change 47 (3): 406-415.

Taaffe, E. J., R. L. Morrill, and P. R. Gould. 1963. "Transport expansion in underdeveloped countries: A comparative analysis." Geographical Review 53: 503-529.

Taylor, P. J., and B. Derudder 2016. World City Network. A Global Urban Analysis. London and New York: Routledge.

Taylor, P. J., M. Hoyler, and R. Verbruggen. 2010. "External urban relational process: Introducing central flow theory to complement central place theory." Urban Studies 47 (13): 2803-2818.

Urry, J., S. Savitzky, and T. Birtchnell 2015. Cargomobilities: Moving Materials in a Global Age. London: Routledge.

Vance, J. E. 1970. The Merchant's World. The Geography of Wholesaling. Englewood Cliffs: PrenticeHall.

Wessa, P. 2018. Free Statistics Software, Office for Research Development and Education, version 1.2.1. https://www.wessa.net/ 


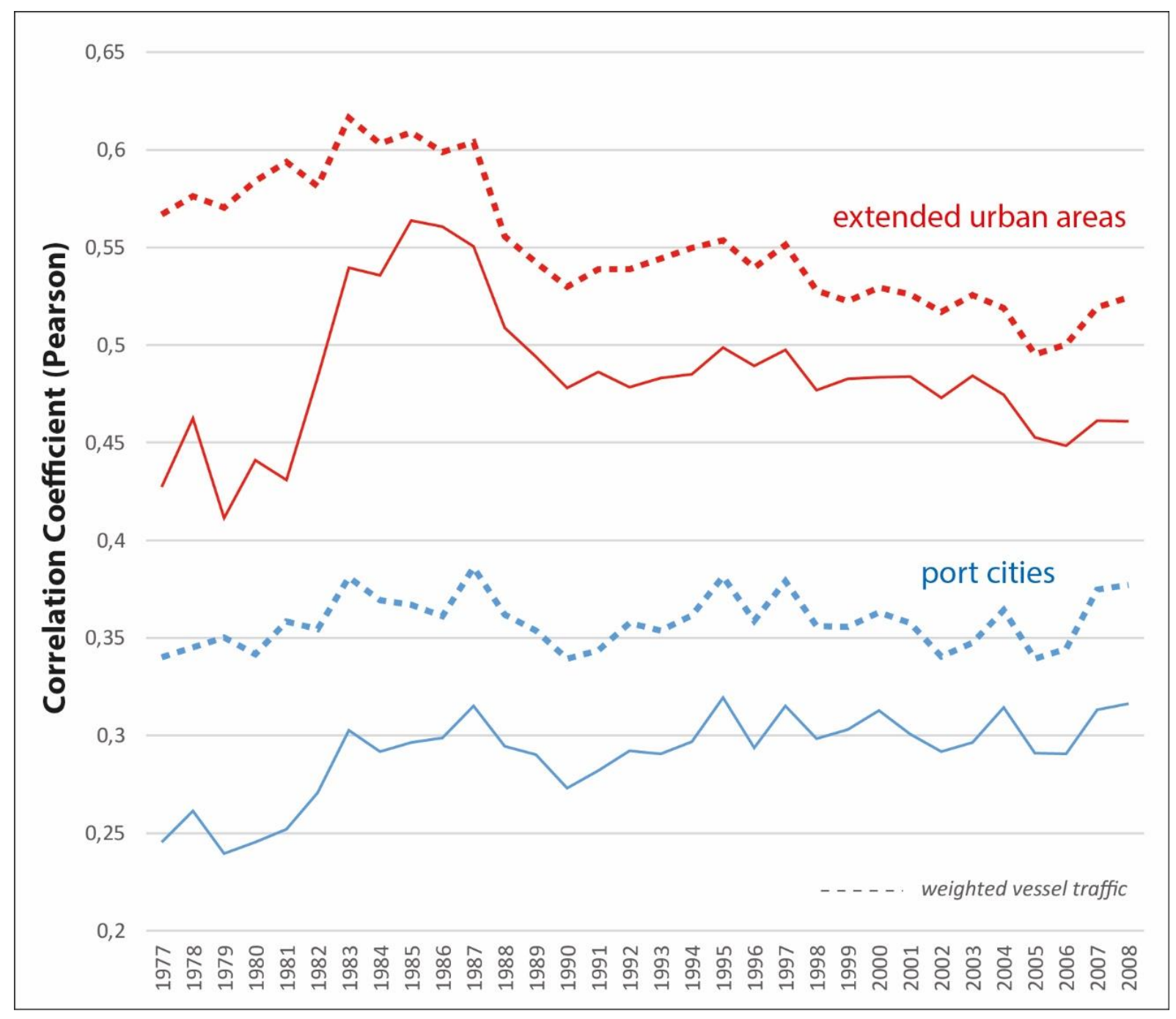

Figure 1: Correlation between urban population and traffic volume, 1977-2008

Source: own realization based on Lloyd's List data and urban data
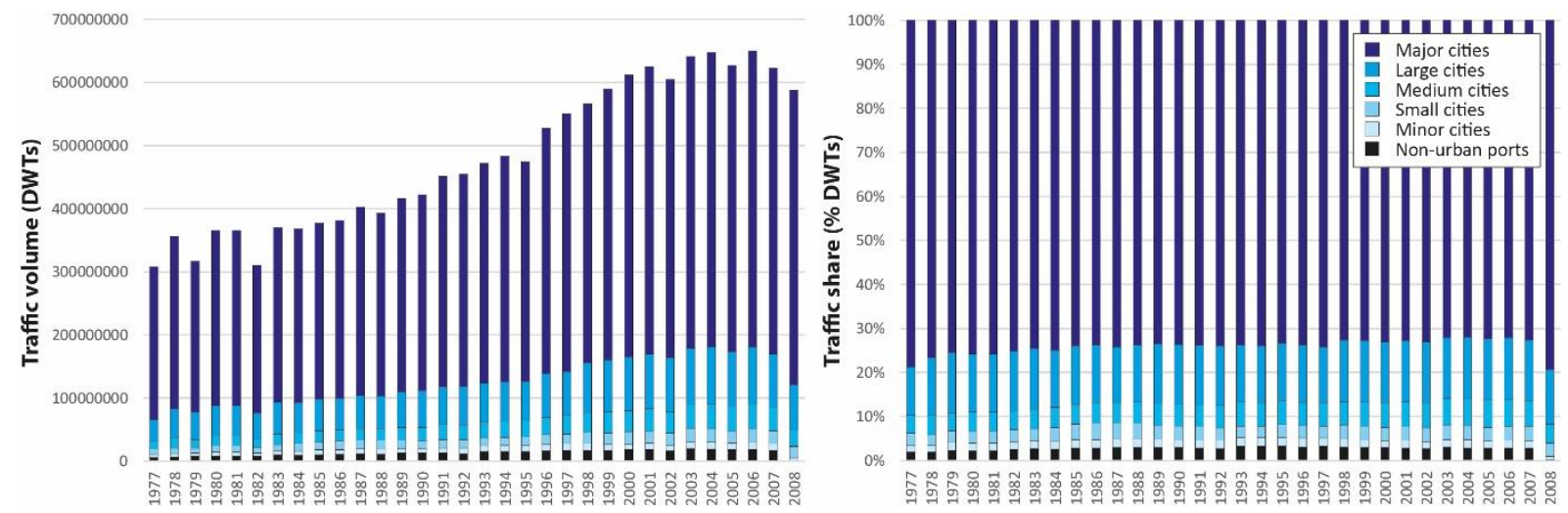

Figure 2: Vessel traffic distribution per urban quantile, 1977-2008

Source: own realization based on Lloyd's List data and urban data 
Correlation coefficient

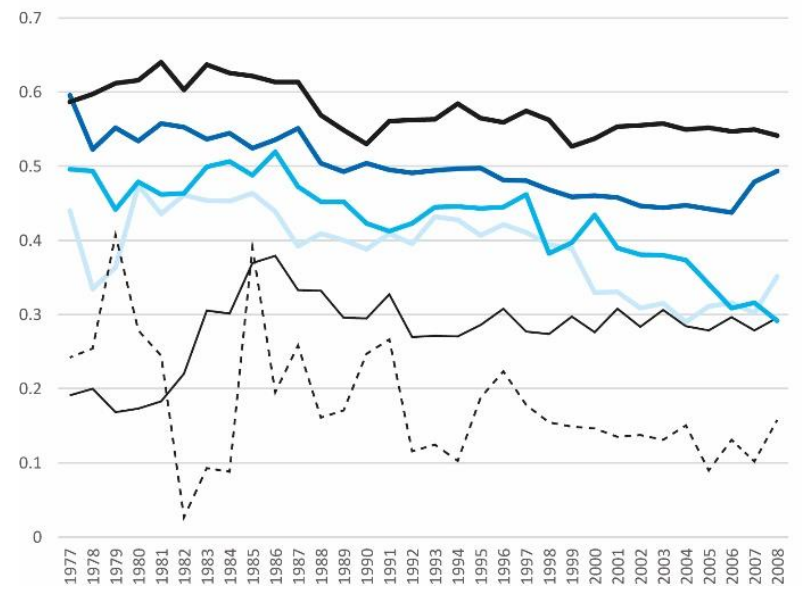

Power-law slope

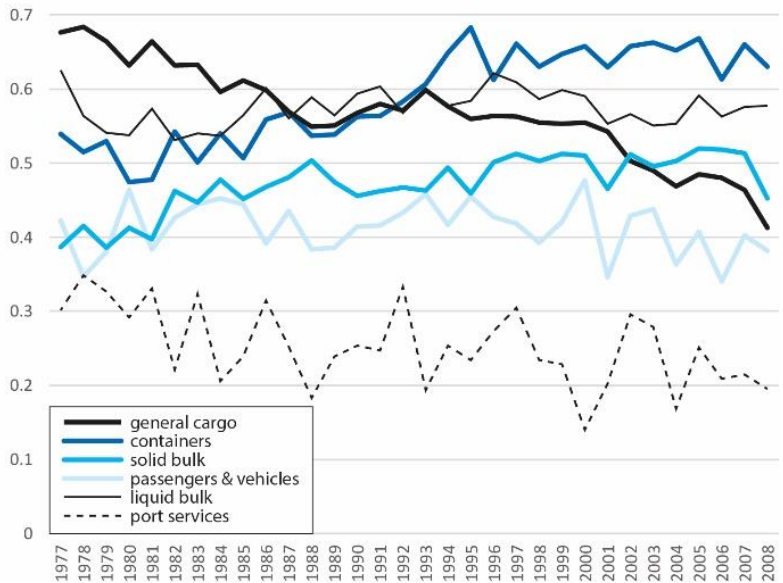

Figure 3: Traffic specialization and city size, 1977-2008

Source: own realization based on Lloyd's List data and urban data
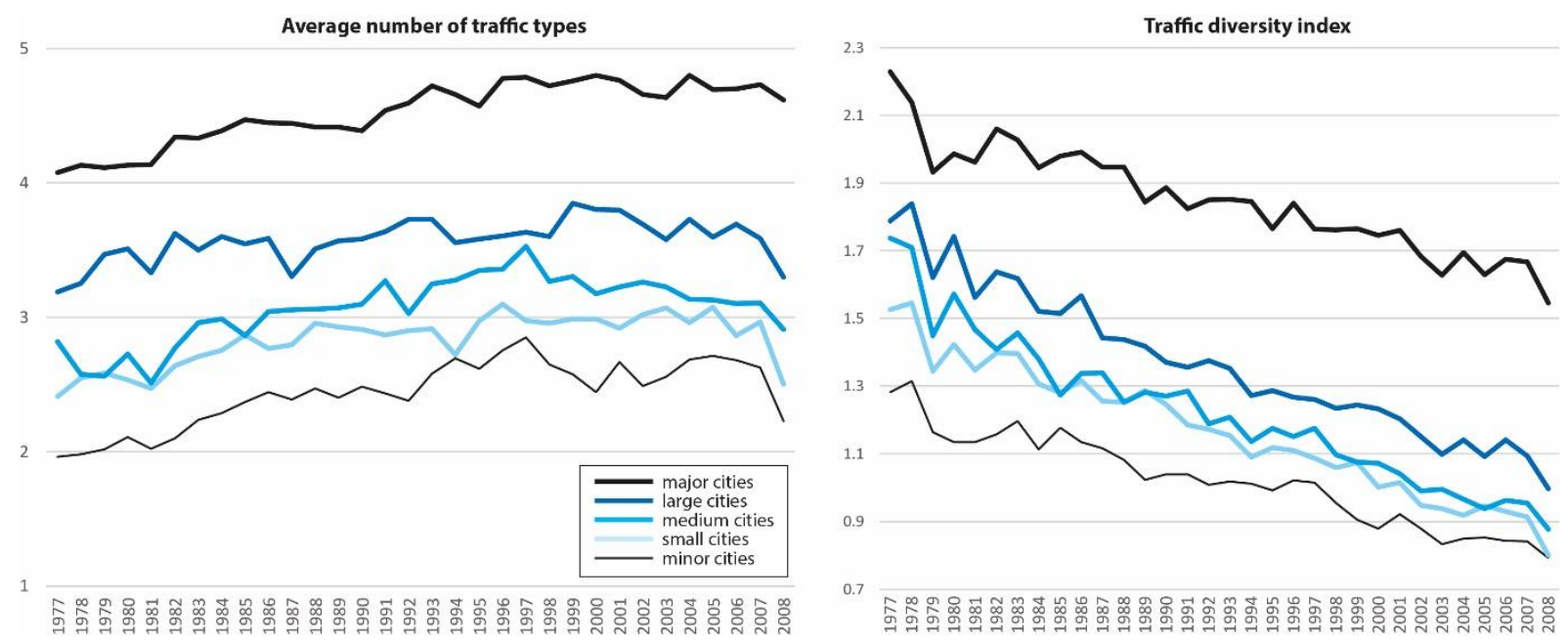

Figure 4: Vessel traffic distribution per urban quantile, 1977-2008

Source: own realization based on Lloyd's List data and urban data 

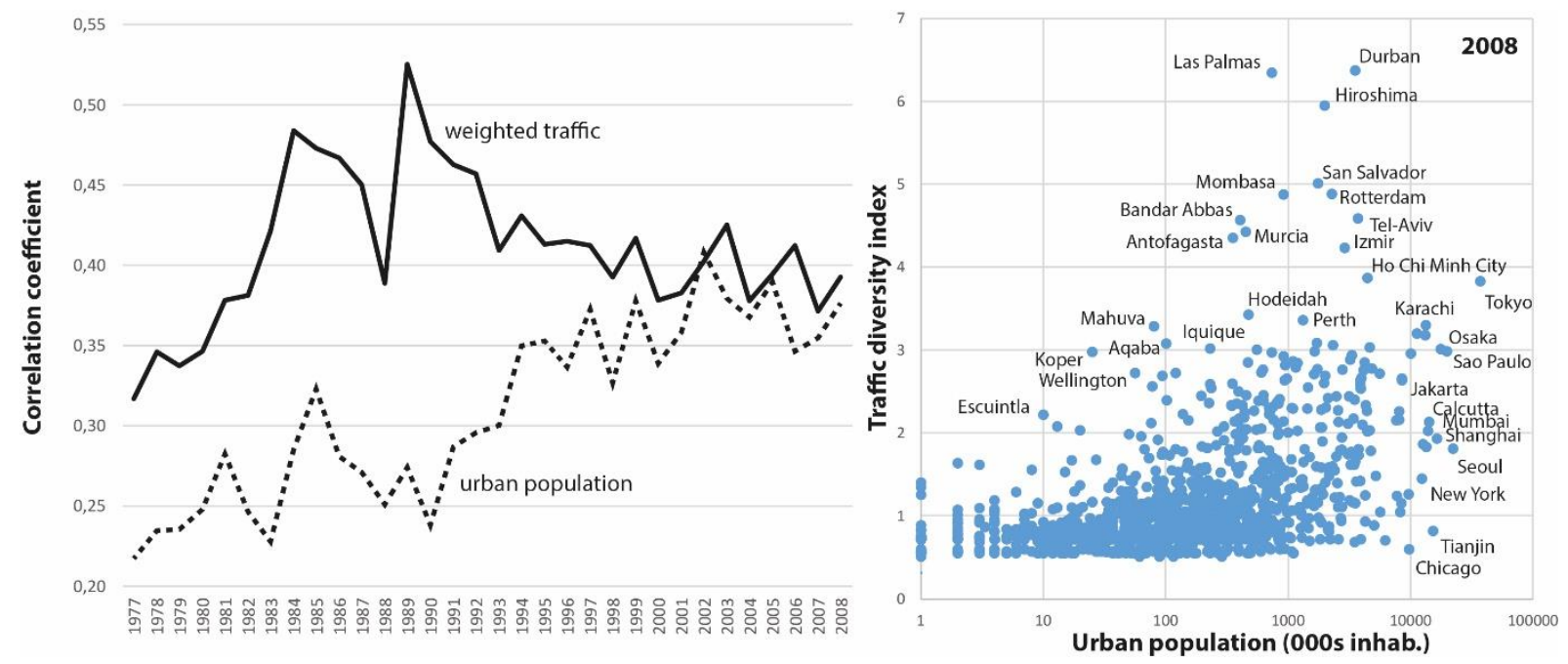

Figure 5: Correlation evolution between traffic diversity, size, and urban population, 1977-2008

Source: own realization based on Lloyd's List data and urban data 


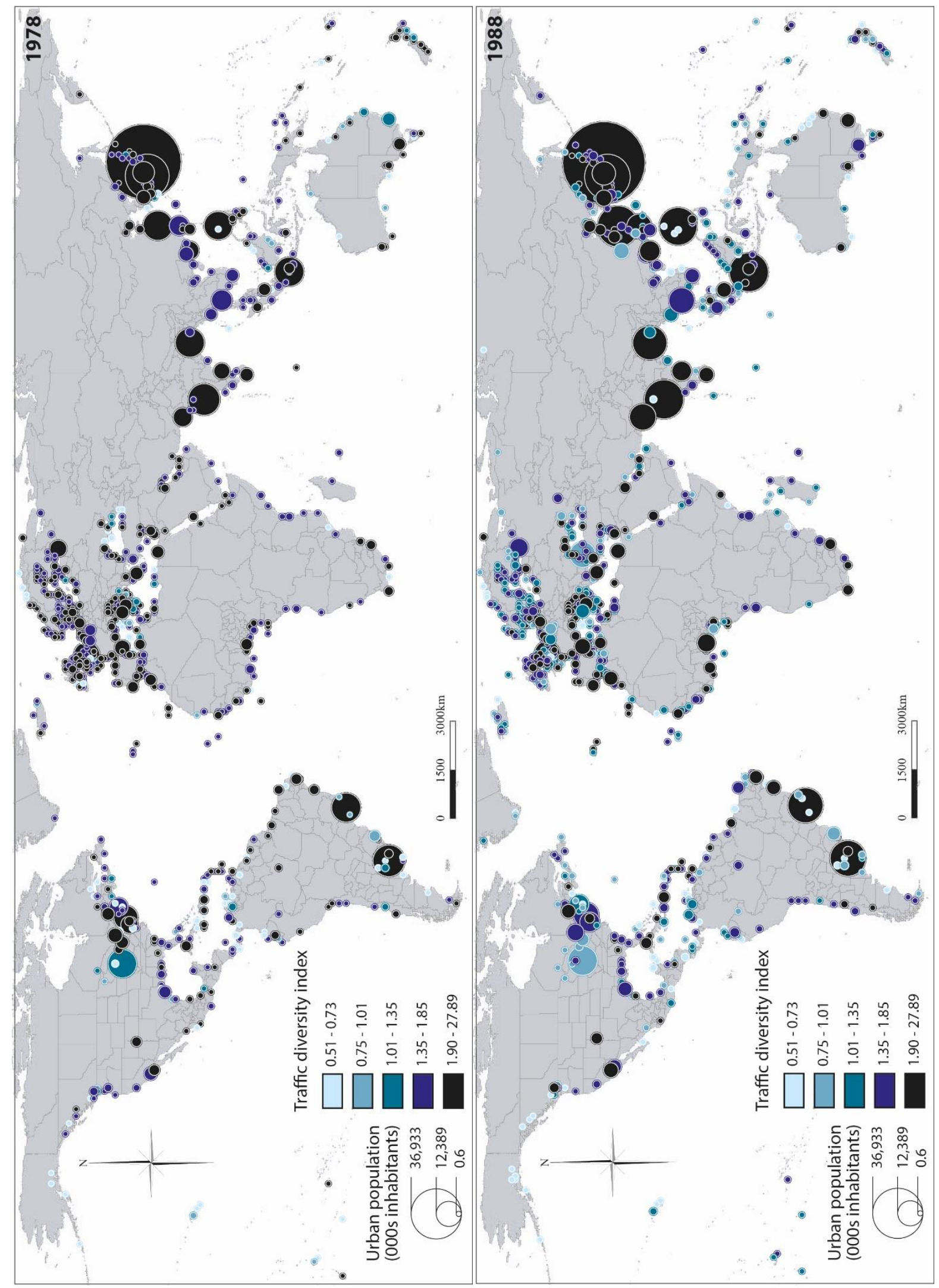

Figure 6: World distribution of traffic diversity and urban hierarchy at selected years

Source: own realization based on Lloyd's List data and urban data 


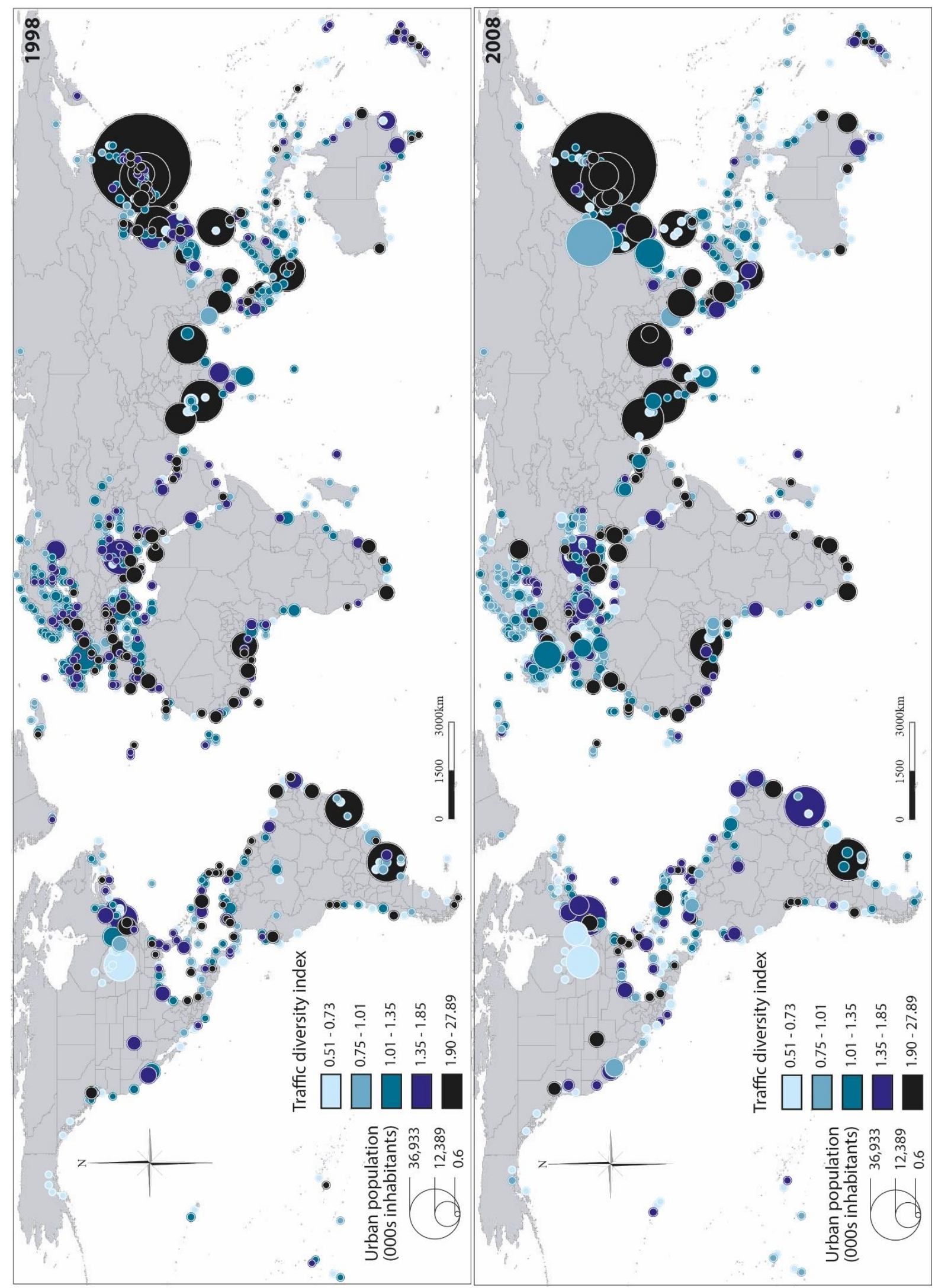

Figure 6 (continued) 

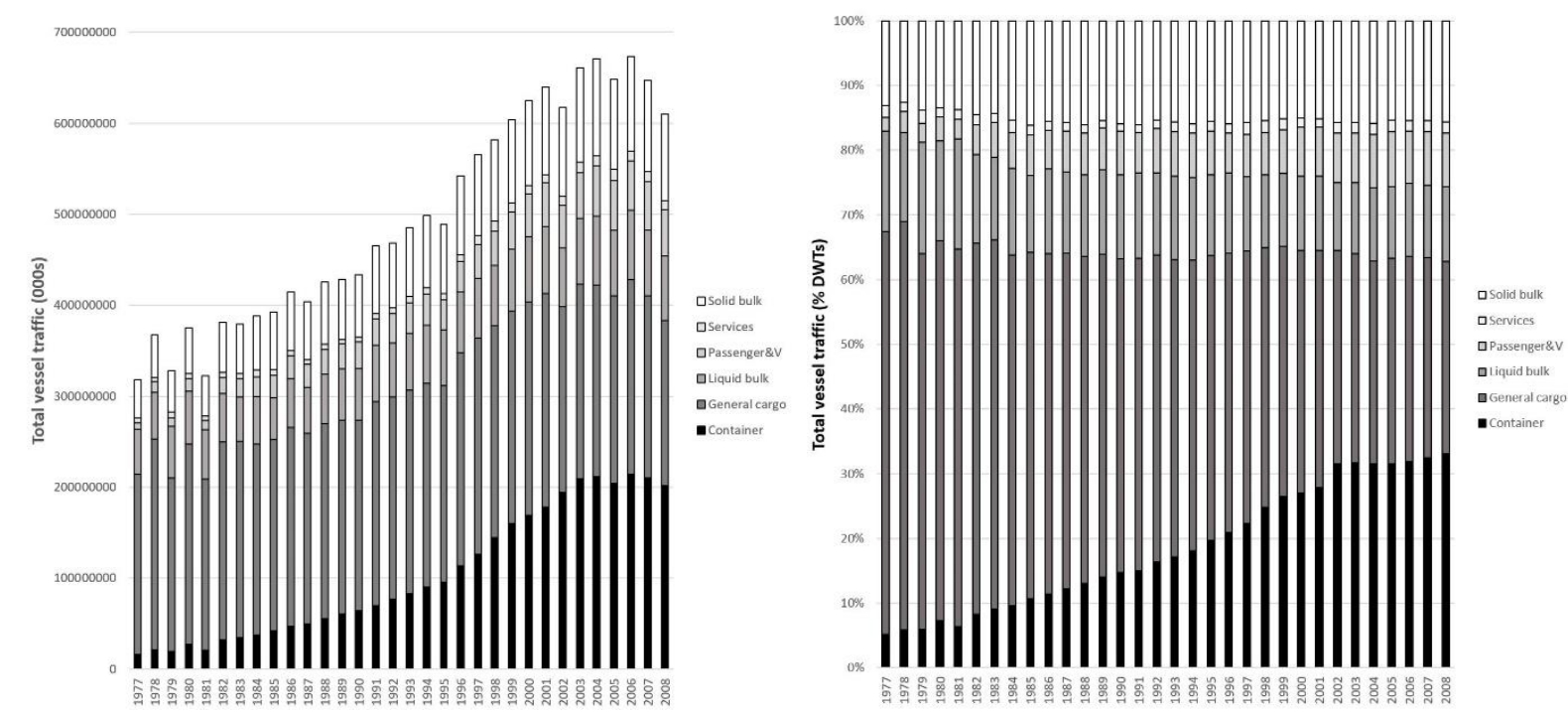

Appendix 2: Traffic evolution per main category, 1977-2008

Source: own realization based on Lloyd's List data

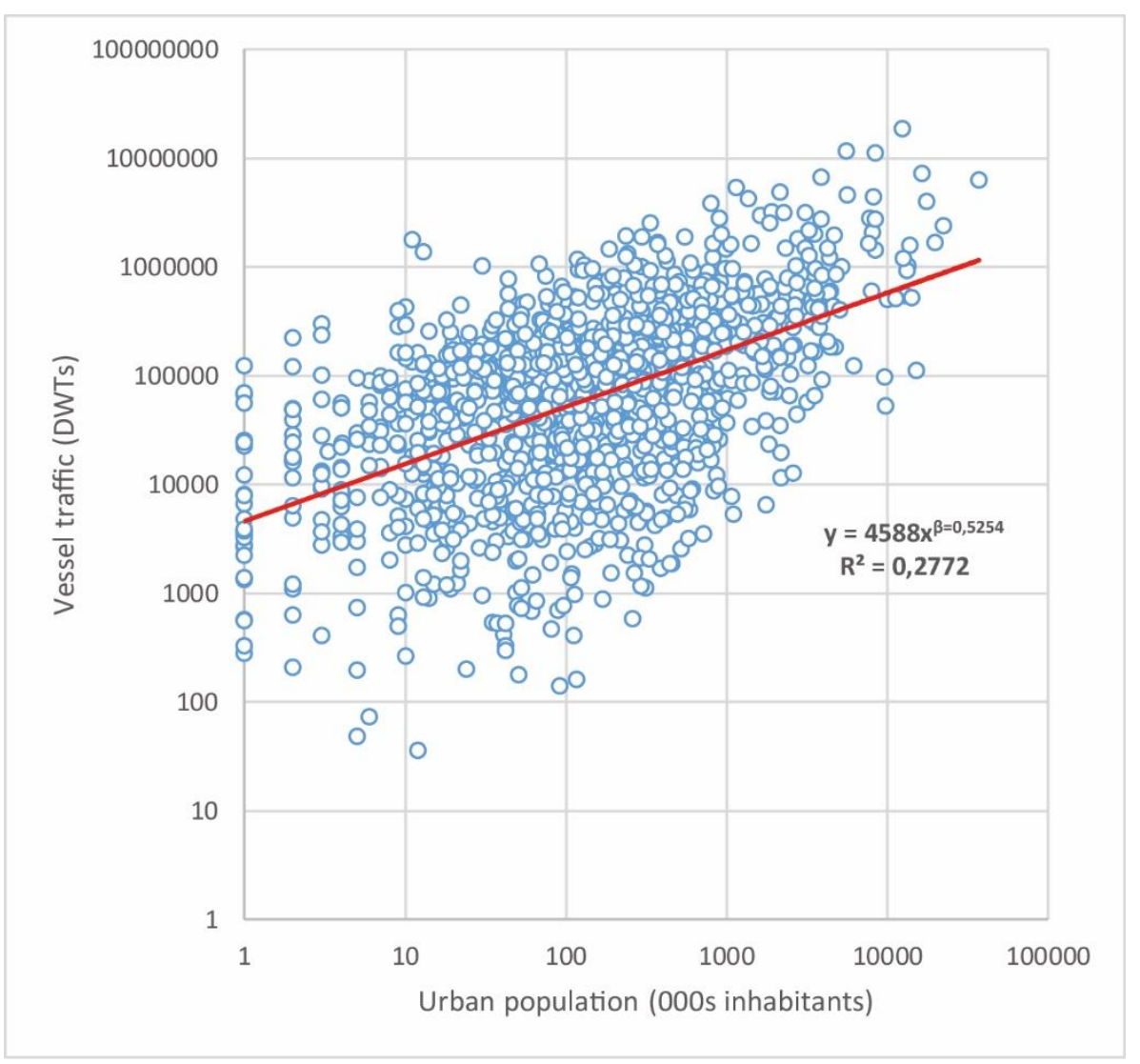

Appendix 4: Example of scaling / power-law analysis in 2008

Source: own realization based on Lloyd's List and urban data 


\begin{tabular}{|c|c|c|}
\hline Type & Subtype & No. vessels \\
\hline \multirow{2}{*}{ Container } & Container & 3,529 \\
\hline & Reefer & 2,176 \\
\hline \multirow{5}{*}{ General cargo } & Container & 6,386 \\
\hline & Fishing & 4,980 \\
\hline & General cargo & 24,494 \\
\hline & Livestock & 293 \\
\hline & Other general & 32 \\
\hline \multirow{8}{*}{ Liquid bulks } & Asphalt & 152 \\
\hline & Chemical & 2,416 \\
\hline & Crude oil & 1,297 \\
\hline & Fishing & 2 \\
\hline & Gas & 1,287 \\
\hline & Molasses & 9 \\
\hline & Oil tanker & 5,069 \\
\hline & Other tanker & 3,866 \\
\hline \multirow{3}{*}{ Passengers \& vehicles } & Cruise & 606 \\
\hline & Passenger & 1,977 \\
\hline & Vehicle & 3,840 \\
\hline \multirow{3}{*}{ Services } & Dredging & 645 \\
\hline & Other service & 7,970 \\
\hline & Research & 812 \\
\hline \multirow{8}{*}{ Solid bulks } & Aggregates & 4 \\
\hline & Cement & 426 \\
\hline & Container (mixed) & 229 \\
\hline & Solid bulk & 8,875 \\
\hline & Oil tanker (mixed) & 473 \\
\hline & Ores & 734 \\
\hline & Other solid & 160 \\
\hline & Wood & 178 \\
\hline
\end{tabular}

\section{Appendix 1: Vessel fleet distribution by type and subtype}

Source: own realization based on Lloyd's List data and urban data 


\begin{tabular}{|c|r|r|r|r|}
\hline Quantile / Year & \multicolumn{1}{|c|}{1977} & \multicolumn{1}{|c|}{1987} & \multicolumn{1}{|c|}{1997} & 2007 \\
\hline \multirow{2}{*}{1} & 1 & 1 & 1 & 1 \\
\cline { 2 - 5 } & 18 & 20 & 22 & 24 \\
\hline \multirow{2}{*}{2} & 19 & 21 & 23 & 55 \\
\cline { 2 - 5 } & 41 & 48 & 51 & 56 \\
\hline \multirow{2}{*}{3} & 42 & 49 & 52 & 125 \\
\cline { 2 - 5 } & 87 & 108 & 120 & 126 \\
\hline \multirow{2}{*}{4} & 88 & 109 & 121 & 374 \\
\cline { 2 - 5 } & 220 & 293 & 330 & 376 \\
\hline \multirow{2}{*}{5} & 221 & 294 & 331 & 35,691 \\
\hline
\end{tabular}

Appendix 3: Urban quantile thresholds (unit: thousands of inhabitants)

Source: own realization based on urban data 